\title{
Sealing Performances Research on PTFE Rotating Seal under Deep-Sea Environment
}

\author{
Xuepeng Cao ${ }^{*}, 1$, Cuihong Zhang ${ }^{1}$, Bo Zou ${ }^{2}$ and Lei $\mathrm{Li}^{3}$ \\ ${ }^{1}$ College of Engineering Machinery, Chang'an University, Xi'an 710064, China \\ ${ }^{2}$ SANY Group Co., Ltd., Changsha 410100, China \\ ${ }^{3}$ Baoji Oilfield Machinery Co., Ltd., 721015, USA
}

\begin{abstract}
In order to improve the environmental adaptability and sealing performance of the rotating seal, the principles and failure mechanisms of the rotating seal in ambient pressure in deep-sea is researched. It is proposed that the excessive friction caused by the ambient pressure and the magnitude of interference is the main reason for rotating seal failure. To reduce friction effect, a combined lip seal is designed, whose structure consists of a rotating seal made of polytetrafluoroethylene (PTFE) and an O-shaped fastening ring. The finite element analysis results indicate that the contact pressure in sealing surface increases with the growing magnitude of interference, but decreases when it exceeds the value $0.65 \mathrm{~mm}$. A suitable range $\left(0.5 \times 10^{-3} \mathrm{~m} \sim 0.6 \times 10^{-3} \mathrm{~m}\right)$ for the magnitude of interference is concluded for this combined seal. Finally, the designed PTFE rotating seal is tested in a deep-sea imitating hull, and the experimental results show that the seal is able to work reliably without leaking for more than 10 hours in the ambient pressure less than $30 \mathrm{MPa}$, and verifies the design of the rotating seal is rational, which displays that the seal is available for the special requirement of deep-sea environment in short periods.
\end{abstract}

Keywords: Contact pressure, deep-sea environment, deep-sea imitating hull test, magnitude of interference, rotating seal.

\section{INTRODUCTION}

The rotating seal is an important sealing form of rotary device in deep sea. It is often used in the motor seal under deep sea to isolate the motor body from seawater. As a key seal form in deep-sea environment, its performances directly determine working pressure and sealing effect. Under the deep-sea, seawater temperature is lower than atmospheric condition, and seawater has highly corrosive. Therefore the rotating sealing structure is required to have the properties of environmental adaptability and corrosion resistance. Currently, the rotating seals in the high-pressure environment include mechanical seals and labyrinth seals [1, 2]. In general, the sealing pressure of single-stage mechanical seal cannot exceed the maximum 10MPa. The two or more stages should be applied in higher pressure. Although this seal structure has low leakage and long service life, the complex structure and large size restrict its application. The labyrinth seal is usually used as a sealing form in the front stage or between stages, and has large leakage. In deep-sea application, the motor's seals require little leakage, and its weight and size are also strictly limited. Therefore, the two types of seals are difficult to adapt this condition.

Several scholars have already studied rotating seals structure in different conditions. Zhao Yi M, et al. [3] developed a tribo-dynamic model for the spiral-groove

*Address correspondence to this author at the College of Engineering Machinery, Chang'an University, Xi'an 710064, China; Tel: +86 02982334496; Fax: +86 02982334496; E-mail: caoxp2011@163.com rotating seal ring through coupling lubrication and dynamic equations, and analyzed the dynamic behaviors and seal characteristics of spiral-groove rotary seal ring under real and step change oil filling conditions, through the establishment of dynamic friction model and global computational scheme, the stable lubricating properties were verified. Dang J.J. et al. [4] discussed the amount of frictional heat on the sealing surface for the specific structure of the high pressure rotating seal in the rotary combustion chamber, researched the contact pressure and friction torque through numerical simulation, studied the rule of the seal wear, and verified the results by wear test. Based on the coal bed methane drilling conditions, Wei X.D. et al. [5] designed a dynamic seal structure of rotary control heads, and established the model by simplifying the sealing structure.

However, all the above three research methods on the rotating seals did not focus on the relationship between the wear of seal rings and increasing heat at the sealing surface, i.e., increased friction results in an increase of heat at the sealing surface, thus accelerating the wear of seal rings. And all of them have not involved the extreme environment of the deep-sea. In this paper, a combination of rotating sealing structure applied in deep-sea is designed by using poly tetra fluoro ethylene (PTFE) as a sealing material, by depending on whose excellent characteristics to improve the sealing life, such as wide temperature range, low frictional coefficient, wide compatibility with the sealed fluid and small wear. At the same time, to obtain better sealing performances, an O-shape fastening ring is adopted as a dynamic compensation for PTFE rotating seal to 
continuously produce a relatively stable contact pressure and keep invariable sealing area.

Generally, the design of rotating seal is usually based on experience and qualitative principles, which are difficult for making a reasonable assessment about sealing performances. In this paper, the important sealing parameters are analyzed, such as the wear deformation of the seal and the distribution of the contact pressure on the sealing interface. Also, the theoretical model which revealed rotating sealing mechanism is established, and the deformation and stress analysis of the combined rotating sealing structure are done by using finite element method. At last, its sealing mechanism and finite element simulation results are verified by the test of deep-sea imitating hull.

In this paper, there are some nonlinear problems in the analysis and calculation of rotating dynamic sealing which include not only geometric nonlinearity and material nonlinearity, but also nonlinearity caused by boundary conditions or loads. The equations should be solved by adopting the iterative increment nonlinear finite element equation [6]. Therefore, it is reasonable to do the deformation and stress analysis for combined rotating dynamic sealing by using the finite element method.

\section{SEALING MECHANISM ANALYSIS}

An analysis is conducive to reveal the service life and the reason behind the failure of the rotating seal, and can give guidelines for the optimization design.

\subsection{The Key Factor Analysis of the Rotating Seal}

The sealing mechanism of rotating seals is the frictional resistance by the magnitude of interference fit with the sealing surface to block off the pressure fluid to be sealed. The literatures $[5,7,8]$ show that the proper friction between the rotating seal and sealed surface was a key factor for effective sealing. Lower friction will lead to smaller sealing pressure, which is insufficient to resist fluid pressure to be sealed, but higher friction will cause severer wear. In addition, if the frictional heat between the contact areas surpasses the heat radiating, thermal accumulation will induce the expansion of sealing ring, which will bring out increased tightening force and larger heat production. And excessive heat will greatly accelerate the wear of the sealing surface and shortens the life of rotating seals

\subsection{Heat and Stress Analysis of Sealing Areas}

\subsubsection{Frictional Heat}

Heat sources in the sealing surface include a variety of reasons, such as the frictional heat in sealing areas, the shearing heat between fluid and sealing surface, and the heat generated by the fluid turbulence caused by the rotating shaft. However, the friction in contact areas is the main heat source, and the heat intensity can be generated as:

$Q=F V$

where $F$ is the friction of sealing surface, $\mathrm{N} ; \quad V$ represents the average linear velocity of sealing surface, $\mathrm{m} / \mathrm{s}$.
The above parameters are two key factors affecting sealing performances. The speed $V$ is a controlled variable, so low speed should give priority in applications when it can be accepted. The other factor $F$ is more complex, which will be analyzed as follows.

\subsubsection{The Friction of Sealing Areas}

When the outer surface of the rotating shaft and the inner seal surface are confined to withstand the load, large contact pressure of some asperities will cause rupture of the liquid lubrication boundary, and the two surfaces will be in touch with each other directly and thus bear several loads $[9,10]$, which is shown as Fig. (1), while other asperities are separated through the liquid membrane $\mathrm{S}$ and the cavity $\mathrm{B}$. The fluid film lubrication areas will produce hydrodynamic lubrication effect when moving and undertaking the other part of load. The load acted on the cavities is very small and can be negligible.

The forces in contact area between the seal and the rotating shaft are shown in Fig. (2). There are two types of friction, i.e., the viscous fluid friction and asperity contact friction.

The viscous fluid friction can be expressed as [9]:

$$
F_{f}=\frac{1}{R_{m}} \int_{0}^{2 \pi} \int_{R_{1}}^{R_{2}}\left(\frac{\mu_{r} \omega}{h}-\frac{h}{2} \frac{\partial p}{r \partial \theta}\right) r^{2} d r d \theta
$$

The asperity contact friction can be denoted as [9]:

$$
F_{c}=\frac{1}{R_{m}} \int_{0}^{2 \pi} \int_{R_{1}}^{R_{2}} \tau_{c} r^{2} d r d \theta
$$

Therefore, the total rotating dynamic friction is:

$$
F=F_{c}+F_{f}
$$

On the other hand, on the basis of the definition of dynamic friction, it also can be expressed as:

$$
F=f_{c} P_{s p}^{\prime}+f_{f} P_{f}=f_{c}\left(P_{s p}+P_{f}\right)+f_{f} P_{f}
$$

where, $P_{s p}$ represents the fastening load, which can be expressed as:

$$
P_{s p}=\frac{\pi P_{\max } W D}{4}
$$

where $R_{m}$ is the average diameter of the sealing surface, $\mathrm{m}, r$ is any diameter of the sealing surfaces, $\mathrm{m} ; \mu$ is the fluid dynamic viscosity coefficient, $\mathrm{Pa} \cdot \mathrm{s} ; \omega$ is the angular velocity , $\mathrm{r} / \mathrm{s} ; h$ is the thickness of the fluid film on the sealing surface, $\mathrm{m} ; R_{1}, R_{2}$ denote the inner and outer diameter of the sealing surface, $\mathrm{m} ; \tau_{c}$ is the shear stress of contact friction, $\mathrm{N} / \mathrm{m}^{2} ; P_{s p}^{\prime}, P_{f}, P_{\max }$ respectively represent the asperity contact pressure, the fluid action load and the maximum contact pressure, $\mathrm{N} ; f, f_{c}, f_{f}$ are the total frictional coefficient, the coefficient of asperity contact friction and the coefficient of viscous friction; $W$ is the contact width along the axial direction, $\mathrm{mm} ; D$ is the shaft diameter, $\mathrm{mm}$. 


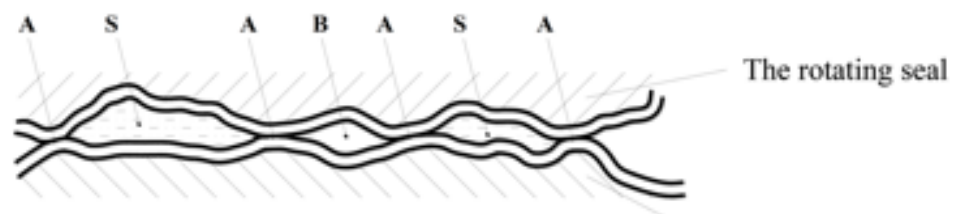

The rotating shaft

A-The asperities B-The cavities S-The fluid films

Fig. (1). The micro contact model of seal ring and rotating shaft.

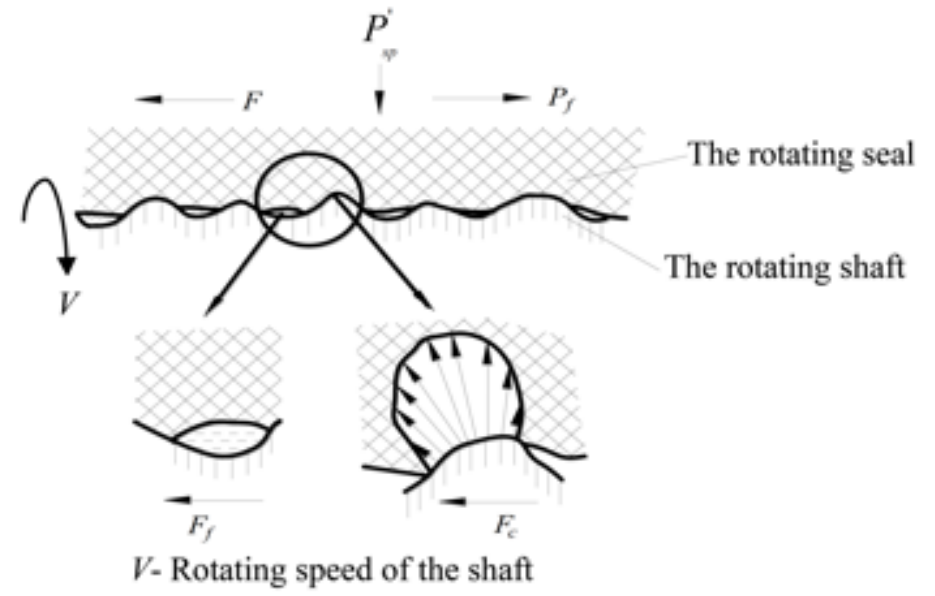

Fig. (2). The forces diagram in contact area of the rotating seal.

From formulas (2) to (6), we can find that the friction of the rotating seal is largely determined by seal size, the magnitude of interference, fastening load and fluid pressure.

(1) The larger the rotating seal size, the greater the total friction $F$. So the radius and width of the rotating seal should be reduced as much as possible in the design and application.

(2) The increasing magnitude of interference between the shaft and the hole of the rotating seal will form thinner film in sealing areas, which will make the viscous friction $F_{f}$ and the contact friction $F_{c}$

between asperities increae. The increased maximum contact pressure indicates that the fastening load increases, which makes the asperity contact friction remarkable. The increasing of magnitude of interference and maximum contact pressure will increase the rotating friction increasing, resulting in the wear and tear of the rotating seal, and vice versa.

(3) The greater viscosity coefficient of sealed fluid, the higher viscous friction. This causes the mobility of hydraulic oil worse, leading to deterioration of heat radiating at the contact surface, and shortening life of the rotating seal.

\section{THE COMBINED STRUCTURE DESIGN FOR PTFE ROTATING SEAL}

A combination of rotating sealing structure involved a rotating body made up of PTFE as the rotary seal and an Oring as the fastening ring. Meanwhile a lip transition is designed to keep a good contact area when the seal is extruded, as shown in Fig. (3). The O-ring instead of the traditional spring is fitted into the slot of PTFE seal with several interference, as shown in place I of Fig. (3). The rotating sealing lip can be hooped tightly on the rotary shaft; meanwhile the O-ring provides an initial contact pressure and produced continuous elasticity, in other words, this continuous elasticity produces a consistent pressure on the lip sealing area. Therefore, the O-ring has a dynamic compensation function in the lip seal, so that stable contact pressure can properly maintain between the PTFE seal lip and the rotating shaft, which is conducive to the film formation with uniform and suitable thickness and improves the sealing performances. Simultaneously taking advantages of the unique self-lubricating property of the PTFE, this structure will largely reduce the asperity contact friction and wear between the sealing areas.

\section{THE FINITE ELEMENT ANALYSIS OF ROTATING SEAL}

The properties of PTFE material vary greatly with the properties of the conventional rubber. The sealing structure and magnitude of interference are analyzed by using the finite element analysis methods. The relationships among the structure size, the magnitude of interference and the contact pressure in the sealing areas are studied, by which the main sealing factors affecting wear are obtained, and the optimal design and rational assembly method about this rotating seals are proposed.

\subsection{Modeling Parameters}

The finite element model of the seal comprises three parts: a PTFE seal, an O-ring and a rotary shaft. The bilinear kinematic hardening material model and the two parameters Moon-Rivlin material model are respectively employed to 


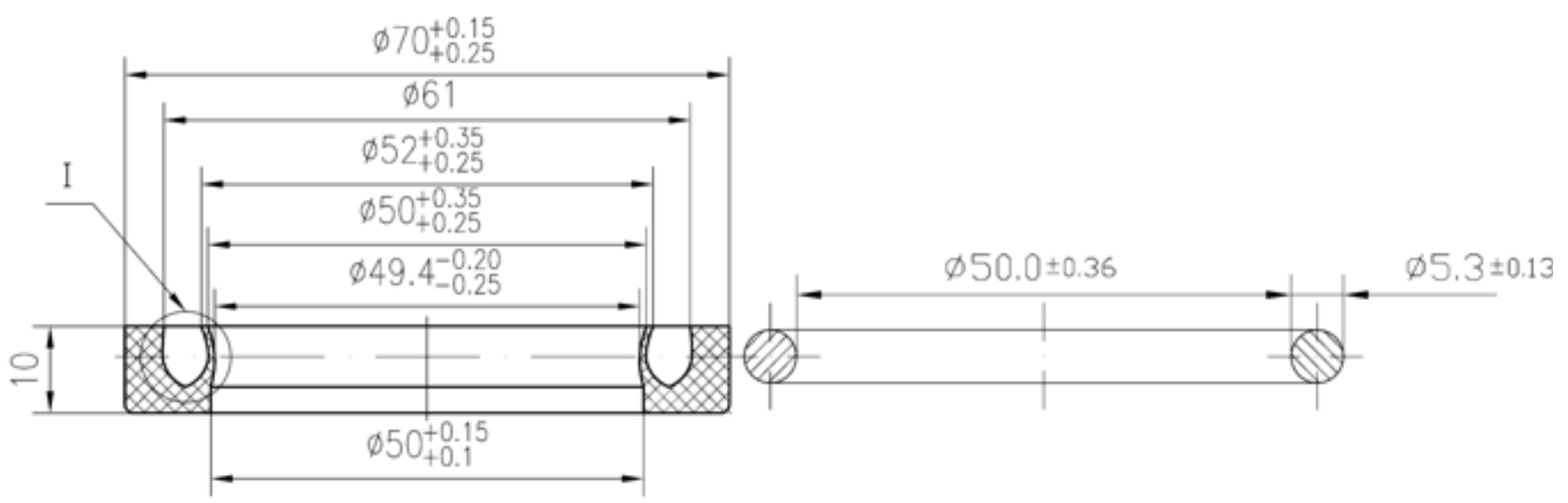

(1) The PTFE seal

(2) The fastening O-ring

Fig. (3). The structures and geometry assembly dimensions of the rotating seals.

Table 1. The material properties values.

\begin{tabular}{|c|c|c|c|c|c|}
\hline & Modulus of Elasticity (GPa) & Yield Strength (MP) & Yield Strain & Tangent Modulus (GPa) & Poisson's Ratio \\
\hline \hline The PTFE seal & 1.0 & $18 \mathrm{MPa}$ & $1.6 \%$ & 0.12 & 0.35 \\
\hline The rotary shaft & 210 & $\geq 355 \mathrm{MPa}$ & - & - & 0.3 \\
\hline
\end{tabular}

simulate the PTFE material and the O-ring. The shaft is $45 \#$ steel. Specific parameter values are shown in Table 1. The finite element model is shown in Fig. (4). The initial contact pressure of O-ring assembled is shown in Fig. (5). The values of $\mathrm{C} 1$ and $\mathrm{C} 2$ in analysis are $1.87 \mathrm{MPa}$ and $0.47 \mathrm{MPa}$ respectively.

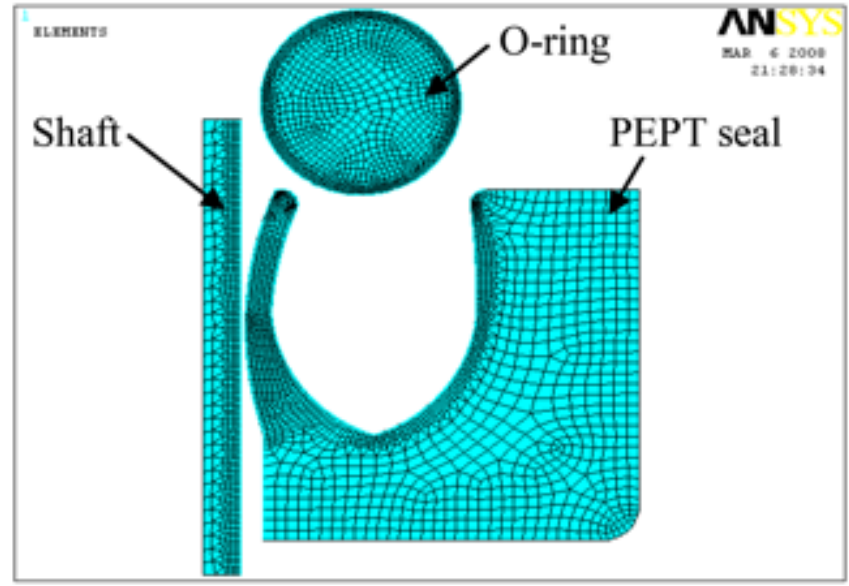

Fig. (4). The finite element model of the lip seal.

\subsection{Simulating Analysis}

Fig. (6) are the contact pressure distribution, corresponding to the magnitude of interference varies from $0.24 \times 10^{-3} \mathrm{~m}, 0.4 \times 10^{-3} \mathrm{~m}, 0.6 \times 10^{-3} \mathrm{~m}$ to $0.8 \times 10^{-3} \mathrm{~m}$. Fig. (7) shows the changes of the maximum contact pressure in the lip area and the Fig. (5) magnitude shows of interference extracted. These figures show that the contact width of the sealing areas increases significantly with the increasing of

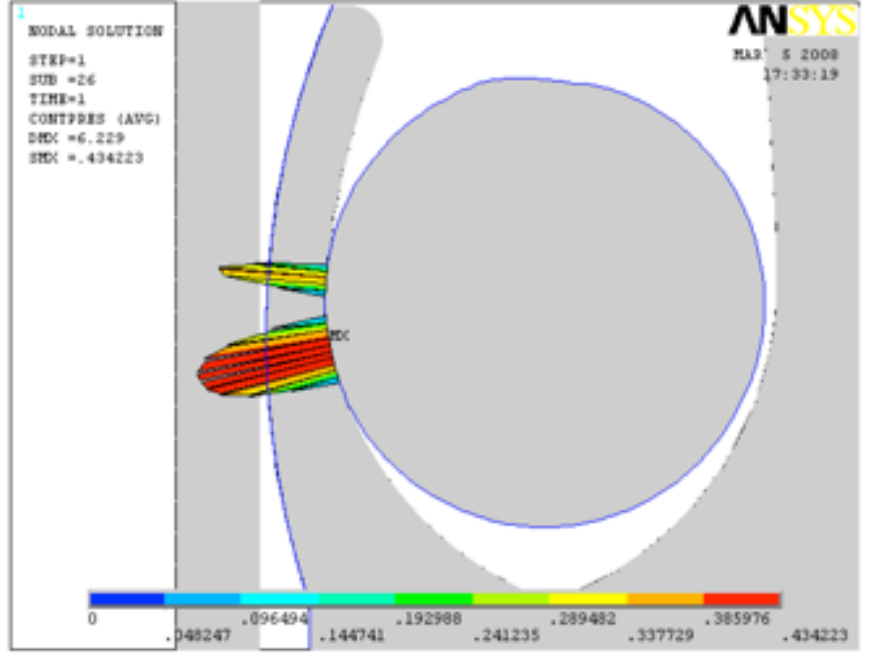

Fig. (5). The contact pressure distribution when the O-shaped ring assembled initially.

magnitude of interference, and the O-ring can provide fastening strength consistently for sealing lip areas with a slight fluctuation within the allowable range. The maximum contact pressure initially increases with the magnitude of interference. When the interference is approaching to $0.6 \times 10^{-}$ ${ }^{3} \mathrm{~m}$, the maximum contact pressure reaches the maximum value $12.2 \mathrm{MPa}$, but following decline. Combining previous theoretical results, the appropriate contact pressure is essential for a reliable seal, which can help to improve the sealing effect and prolong the sealing life. From the analyzed model, the maximum contact pressure is not proportional to the magnitude of interference, which is a maximum. Taking into account the subsequent wear, the maximum contact 


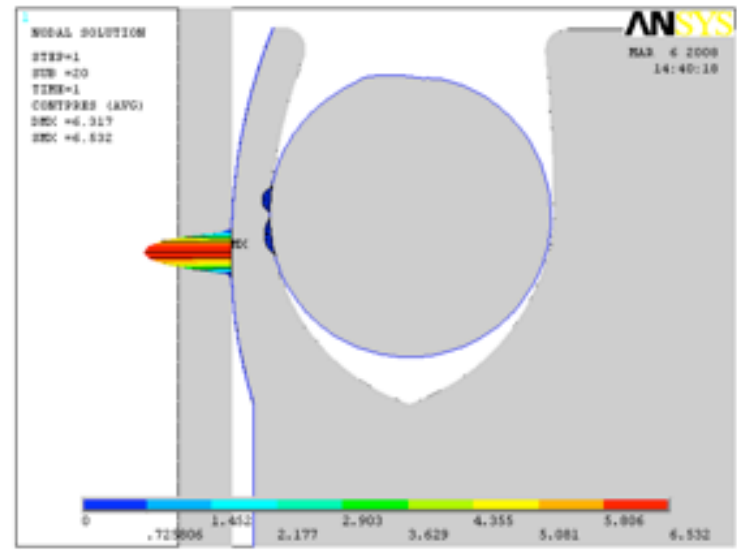

(1) Magnitude of interference is $0.2 \times 10^{-3} \mathrm{~m}$

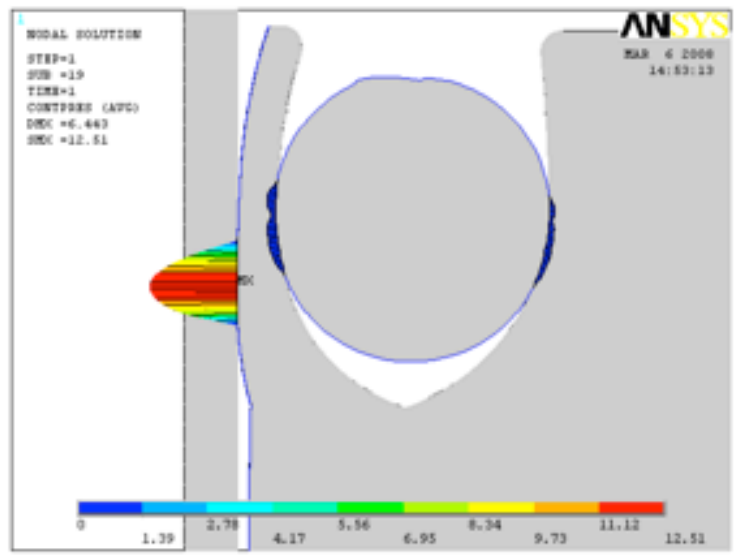

(3) Magnitude of interference is $0.6 \times 10^{-3} \mathrm{~m}$

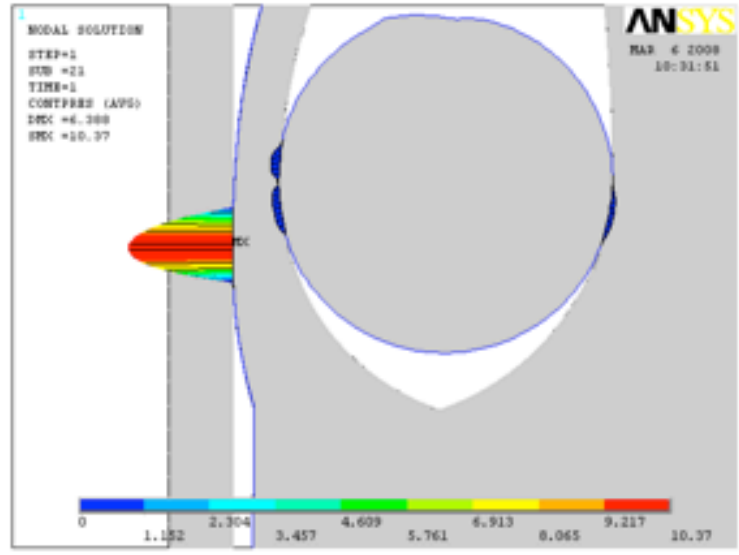

(2) Magnitude of interference is $0.4 \times 10^{-3} \mathrm{~m}$

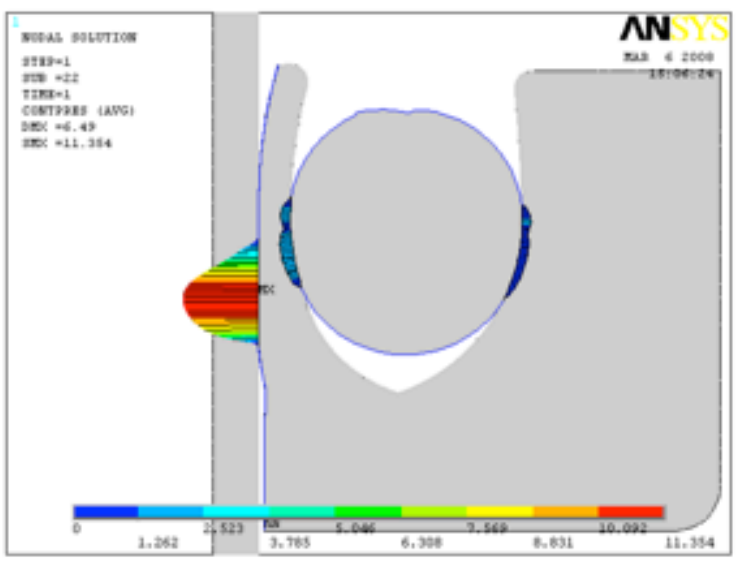

(4) Magnitude of interference is $0.8 \times 10^{-3} \mathrm{~m}$

Fig. (6). The contact pressure distribution at lip area when magnitude of interference varies in $[0.2,0.8] \times 10^{-3} \mathrm{~m}$.

pressure should be kept initially for this combined structure seal. And the corresponding magnitude of interference in the initial assembly should be maintained at $0.6 \times 10^{-3} \mathrm{~m}$.

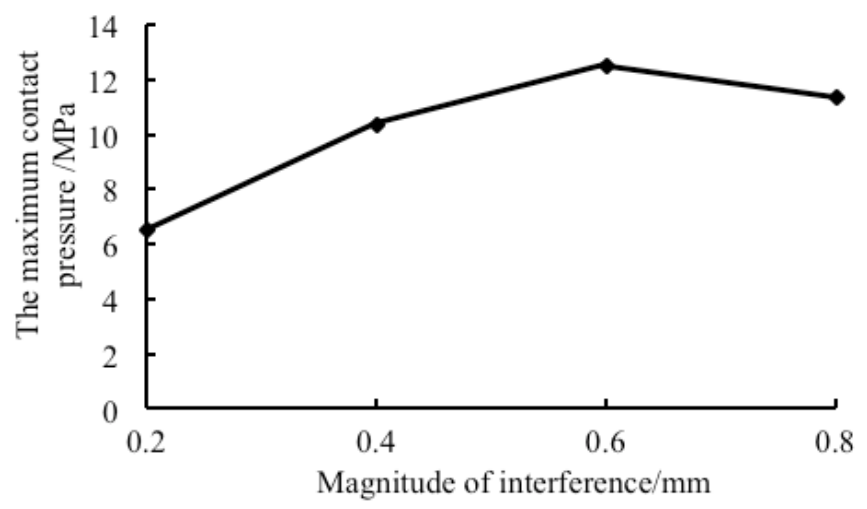

Fig. (7). The maximum contact pressure at lip areas changes with the magnitude of interference varying.

\section{THE EXPERIMENTAL TEST}

In order to verify the effectiveness of the theoretical analysis and simulation results, performance test of the rotating seal in a deep-sea imitating hull has been carried out.

\subsection{Testing Apparatus and Conditions}

In this experiment, a pump supplying 60MPa highpressure oil is used to fill a deep-sea imitating hull, which is an airtight chamber enduring up to $40 \mathrm{MPa}$ ambient pressure simulation. One AC motor, whose rated speed is $1440 \mathrm{r} / \mathrm{min}$, drives a pump built in the hull, and the pump is loaded by an electro-hydraulic proportional valve. The PTFE rotating seal to be tested is mounted between the extending shaft of the pump and the end cap of the imitating hull, which is shown as Fig. (8). The specific assembly sequences of the rotating seal are shown as Fig. (9).

The testing conditions and components are given as following: the test work is done in room temperature; the viscosity coefficient of hydraulic oil is $32 \times 10^{-6} \mathrm{~m}^{2} / \mathrm{s}$. The inner diameter of the rotating seal is $0.0494 \mathrm{~m}$, and the outside diameter of the shaft is $0.05 \mathrm{~m}$. The magnitude of interference is set as $0.6 \times 10^{-3} \mathrm{~m}$. The hierarchical pressurization is used to fill the chamber in this test, and specific pressurizing procedures are shown as Table 2.

\subsection{Analysis of the Test Results}

The test results are shown as Tables $\mathbf{2}$ and $\mathbf{3}$, and Fig. (10). From Table 3, the extending shaft of the pressure hull 


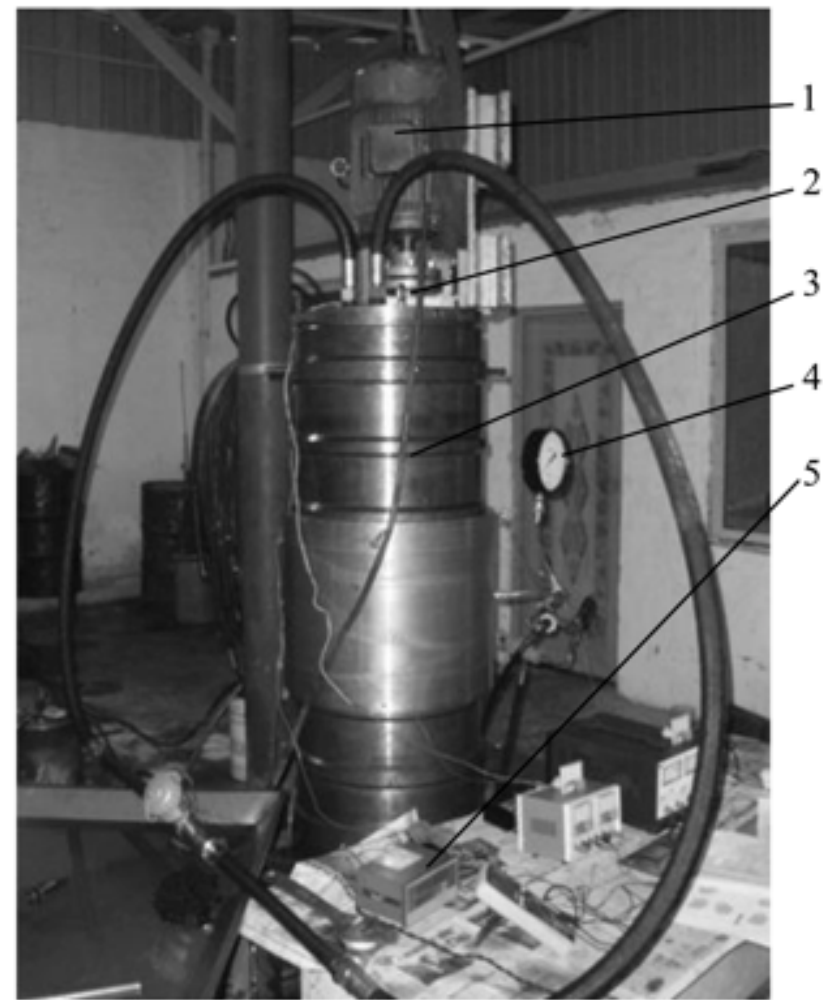

1. Motor 2. Rotating shaft 3.Deep-sea imitating hull

\section{Pressure gauge 5 . Valves amplifier}

Fig. (8). The overall view of the testing apparatus.

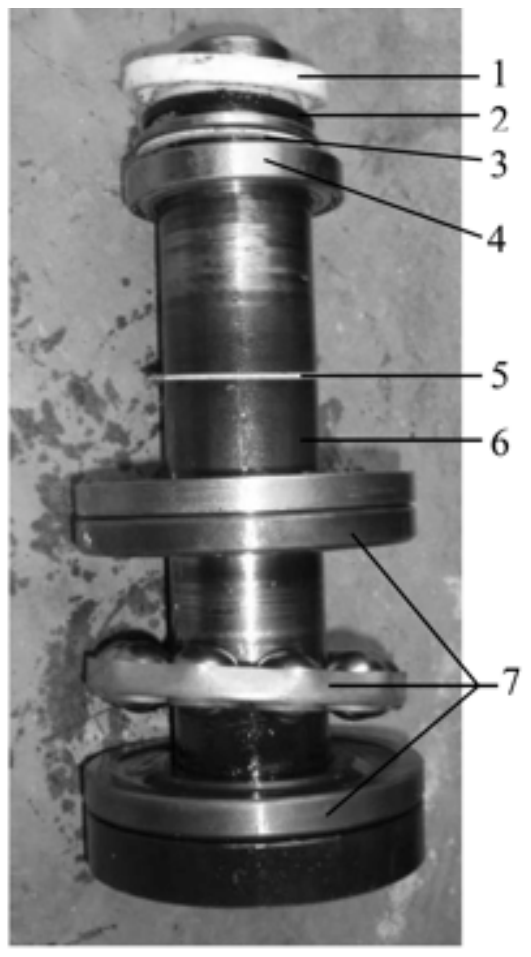

\section{PTFE rotating seal 2. O-ring 3. Collar 4. Ball bearing 5. PTFE gasket 6. Rotating shaft 7. Thrust bearing}

Fig. (9). The assembly sequences picture of the tested rotating seal. did not leak when the rotating seal was tested for about 10 hours, while using ordinary rotating seals, it could only last about half an hour, so this rotating seal is able to meet the special requirements in deep-sea pressure environment for longer time. After the three successive pressure tests, the shaft continued to rotate in the pressure $20 \mathrm{MPa}$, and this process was carried out for about two hours until the leakage occurred, then the fourth test finished. Then while removing the seal, we found out that it was severely damaged (Fig. 10). The sealing lip has been stripped from the PTFE body; meanwhile the fastening O-ring also presented burn damage to some extent. Test results display that when the hull pressure reached the maximum testing pressure, the seal did not fail, however in the last test ambient pressure had less value, but the leakage occurred. Therefore, the main reason for the seal failure is persistently wear, which is closely related with the contact pressure and the magnitude of interference between rotating shaft and the seal.

From Table 3, the axial width and the outer diameter of PTFE seal has changed greatly, the decrement of former parameter is $1.2 \mathrm{~mm}$, while the latter is $1.9 \mathrm{~mm}$, and the wear and tear of inner diameter is especially serious. From the finite element analysis results of the previous, when the magnitude of interference is $0.65 \times 10^{-3} \mathrm{~m}$, the maximum contact pressure of the lip is approach to the maximum value, which will create the friction between the rotating shaft and the seal increase, and bring out strong wear. From the burnt fastening O-ring, it is also seen that much heat was generated by the friction and the sealing region emerged severe heat accumulation. The test results verifies the theoretical analysis that frictional heat would cause thermal expansion of the O-ring and increase the fastening force, which makes more heat production to accelerate the wear of the sealing areas, and eventually lead the failure of rotating seal.

\section{THE OPTIMIZATION ANALYSIS OF THE PTFE ROTATING SEAL}

\subsection{The Selection of Material}

The material of the rotating seal used in this test is on PTFE, whose frictional coefficient is small, but mechanical properties are poor and easy to creep deformation. While the filled PTFE composites, including those filled with carbon fiber, bronze, and molybdenum disulfide, can greatly improve its mechanical properties. Although the frictional coefficient will have a slight increase, the wear resistance will be greatly improved [10]. Therefore, when selecting the material, we should choose the filled PTFE composites to improve the wear resistance of the sealing contact areas, the ability to withstand plastic creep, the thermal stability and hardness value. It is an effective method for enhancing the sealing performances and expanding the service life.

\subsection{The Adjusting of the Magnitude of Interference}

By theoretical analysis and experimental results previously, the magnitude of interference of the rotating seal used in this experiment is a little larger, and worn severely, though the fastening O-ring has the function of dynamic radial compensation. Although theoretical analysis displays 
Table 2. The testing procedures and leaking record.

\begin{tabular}{|c|c|c|c|c|}
\hline Test Sequences & First & Second & Third & Fourth \\
\hline \hline Ambient pressure (MPa) & 10 & 20 & 30 & 20 \\
\hline Running time (h) & 3 & 3.5 & 3 & 2 \\
\hline Test record & No leakage & No leakage & No leakage & Began to leak and the seal failed \\
\hline
\end{tabular}

the high contact pressure make the seal wear and gives an optimal value, it is not easy to get the optimum contact pressure, because this pressure not only depend on calculation, but could also be caused by the deviations including assembly error and processing error. The over contact pressure exerted by magnitude of interference in the test is induced by the later reason. The further experiments show that reasonable controls of these errors can obtain better contact pressure to reduce wear.

Table 3. Comparison of PTFE seal sizes in pre-test and posttest.

\begin{tabular}{|c|c|c|c|}
\hline $\begin{array}{c}\text { The Main } \\
\text { Sizes }\end{array}$ & $\begin{array}{c}\text { Outer } \\
\text { Diameter/mm }\end{array}$ & $\begin{array}{c}\text { Axial } \\
\text { Width/mm }\end{array}$ & $\begin{array}{c}\text { Inner } \\
\text { Diameter/mm }\end{array}$ \\
\hline \hline Pre-test & 70.2 & 10.0 & 49.4 \\
\hline Post-test & 69.0 & 8.1 & The sealing lip damaged. \\
\hline
\end{tabular}

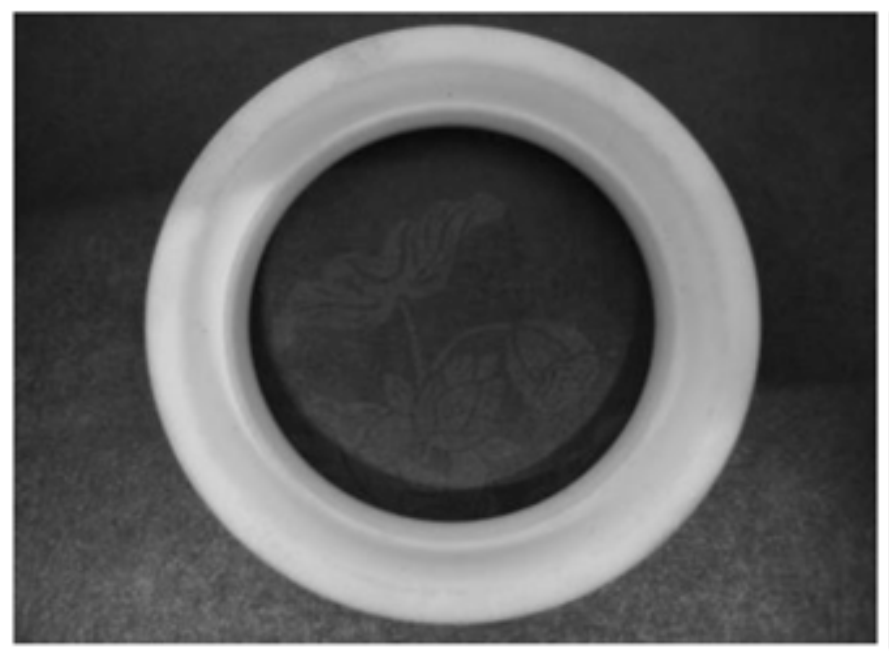

Fig. (10). The comparison chart of PTFE ring before and after test.

Therefore, in order to decrease the contact pressure of the sealing areas, on the one hand, the magnitude of interference between the shaft and the rotating seal should be reduced appropriately in actual sealing devices. On the other hand, the reasonable control for the deviations including assembly error and processing error is also necessary. Under the premise to meeting the sealing requirements, choosing suitable magnitude of interference is another significant approach to relief the wear of the rotating seal.

\section{CONCLUSION}

(1) The sealing mechanism is studied on two aspects including the frictional heat source and the friction in the contact areas for sealing. It is concluded that the important factors affecting performances and service life of the rotating seal involves the size of the rotating seal, the magnitude of interference between the seal and the shaft, maximum contact pressure and fluid viscosity. The increment of these parameters will make the friction increase, and heat production will grow in number, which would accelerate wear and failure of the rotating seal.

(2) By the finite element analyzation of the combined structure of PTFE rotating seal, the relationship between maximum contact pressure and the magnitude of interference is further researched, which displays that the former varies with the varying latter, but exist a maximum. A suitable range $\left(0.5 \times 10^{-3} \mathrm{~m}\right.$

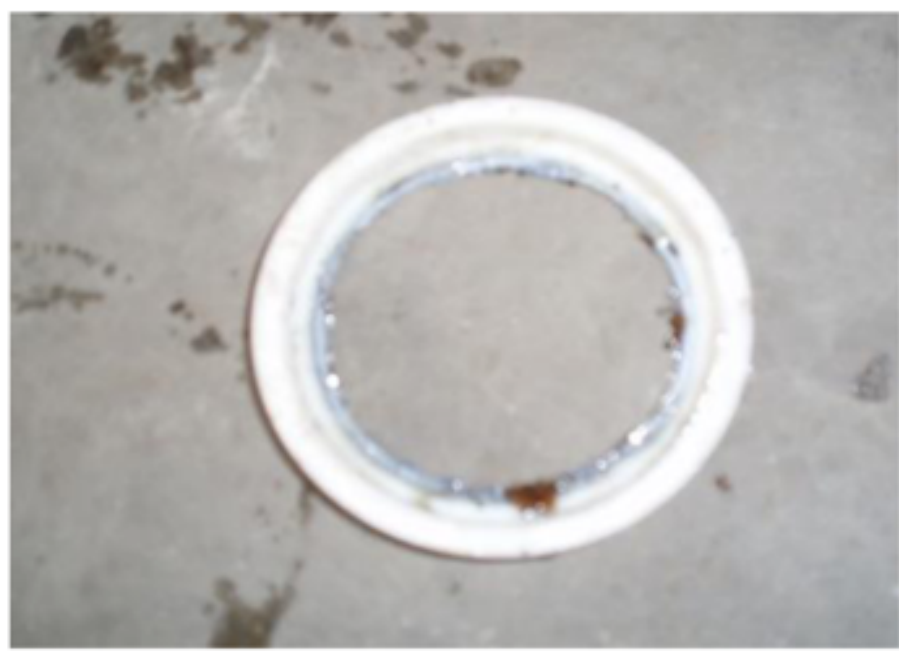

$\sim 0.6 \times 10^{-3} \mathrm{~m}$ ) for the magnitude of interference is concluded for this combined seal.

(3) The test results in the deep-sea imitating hull demonstrates that the PTFE combined rotating seal is able to work reliably without leaking for more than 10 hours in ambient pressure less than $30 \mathrm{MPa}$, which meets the special requirement of deep-sea environment in short period, and verifies that the 
design of the rotating seal is rational. The experiment also indicates that the pure PTFE used in the test is poor in the wear resistance, and adopting the filled PTFE material will be a better alternative in practical applications.

\section{CONFLICT OF INTEREST}

The authors confirm that this article content has no conflict of interest.

\section{ACKNOWLEDGEMENTS}

Fund Project: It is funded by Natural Science Foundation and Shaanxi Provincial Natural Science Foundation (No. 2014JQ7246), and supported by the Fundamental Research Funds for the Central Universities (No. 310825151043).

\section{REFERENCES}

[1] L.R. Cai, Fluid Sealing Technology: Principles And Engineering Applications, Chemical Industry Press: Beijin, 2013.
[2] Q.Y. Gu, Hydrodynamic Seal, Petroleum University Press, 1990.

[3] M. Y. Zhao, B. J. Hu, and C. Wei, "Dynamic analysis of spiralgroove rotary seal ring for wet clutches", Journal of Tribology, vol. 136, no. 3, pp. 31710-1-031710-10, 2014.

[4] Z.J. Dang, K. Luo, and W.Y. Zhang, "Safety research of high pressure rotary seals", Journal of Fluid Machinery, vol. 33, no. 3, pp. 19-21, 2005.

[5] D.X. Wei, Y.Q. Liu, and R.G. Wang, "Structural design and performance analysis of dynamic seals on a rotary control head", Journal of Huazhong, University of Science and Technology (Nature Science Edition), vol. 39, no. 10, pp. 19-27, 2011.

[6] L. Lv, Finite Element Structural Analysis and Examples Based on ANSYS, Chemical Industry Press: Beijing, 2014.

[7] L.K. Zhao, and L.H. Wang, "Analysis of the factors infecting dynamic seal life of rotating BOP", Journal of West Exploration Engineering, no. 3, pp. 51-54, 2011.

[8] S.Z. Sun, "Mechanism and leakage of rotating lip seal", Shanxi Coking Coal Technology, no. 2, pp. 8-10, 2006.

[9] Q.Y. Gu, "Friction coefficient of mechanical seal", Fluid Machinery, vol. 26, no. 4, pp. 19-24, 1997.

[10] H.K. Mnler, B.S. Nan, and Q.C. Cheng, Fluid Sealing Technology: Principles and Applications, Mechanical Industry Press: Beijing, 2002. 